respectively. Patients were classified into latent groups with individuals following a similar course of disease activity and HRQoL. These trajectories were estimated by Group-Based Trajectory Modelling. Next, the trajectories were profiled by comparing the latent groups with respect to baseline factors with ANOVA and Chi-square test.

Results: Five dual trajectories were revealed (Figure): 1. Low impact of AS on patient (13\%): stable low ASQoL and ASDAS inactive disease; 2. Moderate impact (24\%): stable moderate ASQoL and ASDAS high disease; 3 . Improving impact (21\%): major improvement in ASQoL and ASDAS; 4. High impact (29\%): moderately severe ASQoL with very high but improving ASDAS; 5 . Very High Impact (13\%): persistently severe ASQoL with high ASDAS. Low impact of AS was mainly characterized by male gender and HLA-B27; improving impact by younger age, short symptom duration, and biological intake; high impact by higher age, long symptom duration, and (bridging) syndesmophytes (Table).

Conclusions: We identified five dual trajectories of disease activity and HRQoL, each demonstrating a clear mutual relationship. These trajectories and their profiles provide insight into the heterogeneity of the impact of AS on patients' health and overall functioning.

Disclosure of Interest: None declared

DOI: 10.1136/annrheumdis-2017-eular.3802

\section{FRI0432 CLINICAL WORSENING ACCORDING TO THE PATIENT IS INFREQUENT IN AXIAL SPONDYLOARTHRITIS: RESULTS OF THE ASAS-FLARE STUDY IN 1169 PATIENTS}

$\underline{\text { A. Moltó }}^{1}$, B. Meghnathi ${ }^{1}$, L. Gossec ${ }^{2}$, R. Landewé ${ }^{3}$, D. van der Heijde ${ }^{4}$ M. Dougados ${ }^{1}$ on behalf of ASAS-FLARE study group. ${ }^{1}$ Paris Descartes University, Medicine Faculty; APHP, Rheumatology B Department, Cochin Hospital; ${ }^{2}$ Sorbonne Universités, UPMC Univ Paris 06; AP-HP, Pitié Salpêtrière Hospital, Department of rheumatology, Paris, France; ${ }^{3}$ Department of Clinical Immunology \& Rheumatology, Amsterdam Rheumatology Center, Amsterdam and Zuyderland Medical Center, Heerlen; ${ }^{4}$ Department of Rheumatology, Leiden University Medical Centre, Leiden, Netherlands

Background: Prevalence of flares/worsening of the disease in axSpA is not well known, with prevalences ranging from 10 to $40 \%$.

Objectives: To evaluate the prevalence of disease worsening according to the patient's perception in an axSpA population with stable disease and its correlation with disease activity parameters.

Methods: Study: International multicentric (20 countries) longitudinal (2 visits: 1 week - 6 months) observational in 2016, under the guidance of ASAS. Patients: axSpA patients with stable disease according to the rheumatologist. Data on disease characteristics were collected at baseline, and data on disease activity were collected at both visits. Disease worsening was defined at the follow-up visit by the patient using the MCID question ("Think about all the ways your spondyloarthritis has affected you during the last 48 hours. Compared to the last visit how did you feel during the last 48 hours? Improved/No change/Worse"). If patients answered "worse", they marked if they considered themselves in an acceptable symptoms state (PASS) and whether they considered treatment intensification was necessary. Analyses were descriptive and changes in disease activity were calculated according to patient-reported worsening

Results: Among the 1639 patients included, 1169 patients had complete data. Patients were predominantly males $(64.8 \%)$, had a mean age and disease duration of of 41.7 (SD 12.4) and 12.6 (9.9) years, respectively. History of X-ray sacroiliitis, MRI sacroiliitis and HLAB27+ were present in $944(80.8 \%)$, $471(40.6 \%)$ and $807(69.0 \%)$ patients, respectively. 56\% $(n=655)$ patients were receiving a biologic treatment. At the baseline visit, mean BASDAI (0-10) was 3.1 (2.3), mean ASDAS $2.3(1.0)$ and mean CRP $8.4 \mathrm{mg} / \mathrm{L}$ (14.5). Mean interval between both visits was $91.2(51.0)$ days. At the follow-up visit, $590(50.5 \%)$, $388(33.2 \%)$ and $191(16.3 \%)$ patients considered their condition had improved, not changed and worsened, respectively. Among the 191 patients reporting a worsening, $123(64.4 \%)$ considered their symptom status unacceptable, and 127 $(66.5 \%)$ judged their state required treatment intensification. BASDAI, ASDAS and CRP significantly increased in patients considering themselves worsening (Table).

\begin{tabular}{lccc}
\hline & Worsening & Not worsening & \\
\hline Change in BASDAI $(0-10)^{\star}$ & $1.3(1.8)$ & $-0.5(1.5)$ & $<0.005$ \\
Change in ASDAS* & $0.7(0.8)$ & $-0.3(0.8)$ & $<0.005$ \\
Change in CRP $(\mathrm{mg} /)^{\star}$ & $4.5(14.1)$ & $-2.0(13.2)$ & $<0.005$ \\
\hline
\end{tabular}

${ }^{*}$ Change is calculated as the absolute change between the visits; ${ }^{* \star}$ including improvement and no change in status.

Conclusions: in this real-life study of stable axSpA, worsening, as defined by the patient, was not frequent, but was significantly associated with increase in disease activity measures, including objective parameters such as CRP and not only patient-reported outcomes.

Acknowledgements: This study was supported by ASAS (Assessment in SpondyloArthritis international Society)

Disclosure of Interest: None declared

DOI: 10.1136/annrheumdis-2017-eular.4766

\section{FRI0433 HIGH PREVALENCE OF HIDRADENITIS SUPPURATIVA IN PATIENTS WITH AXIAL SPONDYLOARTHRITIS}

S. Arends ${ }^{1,2}$, A. Rondags ${ }^{3}$, F. Wink ${ }^{2}$, B. Horváth ${ }^{3}$, A. Spoorenberg ${ }^{1,2}$

${ }^{1}$ Rheumatology and Clinical Immunology, University Medical Center Groningen, Groningen; ${ }^{2}$ Rheumatology, Medical Center Leeuwarden, Leeuwarden;

${ }^{3}$ Dermatology, University Medical Center Groningen, Groningen, Netherlands

Background: Axial spondyloarthritis (SpA) is associated with several extraarticular manifestations such as the skin disease psoriasis. On the other hand, SpA was found to be more prevalent $(3-4 \%)$ in patients with another skin disease: hidradenitis suppurativa (HS). ${ }^{1} \mathrm{HS}$ is a chronic, recurrent, debilitating inflammatory skin disease that involves deep-seated painful nodules in the inverse body regions, with an average prevalence of $1 \%$ in the European population and a female predominance (ratio $3: 1) .^{2}$ Thus far, the prevalence of HS in axial SpA is not exactly known.

Objectives: To investigate the prevalence of HS in patients with axial SpA.

Methods: A self-screening questionnaire with validated questions concerning HS signs and symptoms including prototypical pictures was send to all participating patients from the Groningen Leeuwarden axial SpA (GLAS) cohort in 2016. All patients fulfilled the ASAS axial SpA criteria. Self-reported HS symptoms were verified by checking medical records and/or verification by phone, defined as diagnosis of HS by a dermatologist.

Results: In total, 588 questionnaires were send to the GLAS patients, of which 459 were returned and could be included in the final analysis (response rate $78 \%$ ). Of the included patients, mean age was $50 \pm 13$ years, $63 \%$ were male, mean symptom duration was $23 \pm 13$ years, and $78 \%$ were HLA-B27 positive.

The questionnaire data showed a high self-reported HS prevalence of $11 \%$. HS symptoms were confirmed by doctor's diagnosis in the large majority of these patients $(41 / 50 ; 82 \%)$, resulting in an estimated HS prevalence of $9 \%$.

The next step will be the comparison of patient characteristics and clinical assessments between axial SpA patients with and without HS.

Conclusions: The present observational cohort study shows that HS is a common skin disease in patients with axial SpA.

References:

[1] Richette et al. J Rheumatol 2014;41(3):490-4.

[2] Zouboulis et al. J Eur Acad Dermatol Venereol 2015;29(4):619-44

Disclosure of Interest: None declared

DOI: 10.1136/annrheumdis-2017-eular.6120

\section{FRI0434 POOR QUALITY OF LIFE IN PATIENTS WITH SPONDYLOARTHRITIS IS NOT EXPLAINED BY STRUCTURAL DAMAGE. DATA FROM REGISPONSER}

C. López-Medina, P. Font-Ugalde, J.L. Garrido-Castro, M.C. Castro-Villegas, J. Calvo-Gutiérrez, R. Ortega-Castro, A. Escudero-Contreras,

E. Collantes-Estévez on behalf of REGISPONSER working group.

Rheumatology, Hospital Universitario Reina Sofía de Córdoba/ Imibic/

Universidad de Córdoba, Córdoba, Spain

Background: In recent years it has become increasingly important the evaluation of the global impact of the disease in patients with Spondyloarthritis ( $\mathrm{SpA}$ ) through the use of the Patient-reported Outcomes (PROs) (1). One of the most used PROs is the Ankylosing Spondylitis Quality of Life (ASQoL) questionnaire, which refers to Health-Related Quality of Life (HRQoL). Since this is a subjective and multifactorial outcome (2), our goal is to detail the most important factors which are related with the Quality of Life $(\mathrm{QoL})$ in these patients.

Objectives: To evaluate QoL in patients with SpA and to define its association with disease-related factors and patient's features.

Methods: A cross-sectional multicenter study which includes 2229 patients with $\mathrm{SpA}$ selected from the national Spondyloarthropaties Spanish Registry (REGISPONSER). The main outcome was the assessment of QoL performed through the ASQoL questionnaire. Subsequently, we studied its relation with different factors organized into 5 groups: sociodemographics, emotional, functionality, disease-related factors and disease activity. Univariate logistic regressions and a multiple linear regression (considering ASQoL as a qualitative dichotomous and quantitative variable respectively) were performed to relate QoL with the studied covariates.

Results: The mean ASQoL score in the entire population studied was 6.09 \pm 5.12 . The average age was $47.74 \pm 13.26$ years old and $698(31.31 \%)$ were women. In univariate logistic regressions, significant differences $(p<0.05)$ were seen in many variables included in the 5 groups: poor QoL (ASQoL $\geq 9$ ) is related with gender (female), age, mental and physical component from SF-12 questionnaire, disease duration, inflammatory back pain (IBP), alternating buttock pain, BASRI (Bath Ankylosing Spondylitis Radiographic Index), BASFI (Bath Ankylosing Spondylitis Functional Index), BASDAI (Bath Ankylosing Spondylitis Disease Activity Index), ESR (Erythrocyte Sedimentation Rate) and global patient's VAS (Visual Analogue Scale), among others.

Finally, multivariate linear regression showed that $61.1 \%$ of the variability of ASQoL ( $\left.R^{2}=0.611, p<0.001\right)$ is explained by sex (female), physical component and 2nd item form SF-12 questionnaire (related to functionality), 6th and 7th items form SF-12 (both related to mental status), global patient's VAS, BASFI and BASDAI.

Conclusions: Poor QoL in SpA patients can be explained by high disease activity 
and by a deterioration in functionality and mental status. However, clinical form of $\mathrm{SpA}$, disease duration and structural damage in spine do not explain this decrease of QoL.

References:

[1] Machado P, Landewé R, Braun J, Hermann KG, Baraliakos X, Baker D, et al: A stratified model for health outcomes in ankylosing spondylitis. Ann Rheum Dis 2011;70:1758-64.

[2] Fernández-Carbadillo C, Navarro-Compán V, Castillo-Gallego C, CastroVillegas MC, Collantes-Estévez E, de Miguel E. Disease activity is the major determinant of quality of life and physical function in patients with early axial Spondyloarthritis: Results from the ESPERANZA Cohort. Arthritis Care Res (Hoboken) 2016 Apr 25.1.

Disclosure of Interest: None declared

DOI: 10.1136/annrheumdis-2017-eular.2071

\section{FRI0435 COMPARISON BETWEEN CENTRAL AND LOCAL ASSESSMENT OF RADIOGRAPHIC SACROILIITIS IN PATIENTS WITH RECENTLY DIAGNOSED AXIAL SPONDYLOARTHRITIS IN PROOF STUDY}

D. Poddubnyy ${ }^{1}$, R.D. Inman ${ }^{2}$, J. Sieper ${ }^{1}$, H. Haibel ${ }^{1}$, M. Hojnik ${ }^{3} \cdot{ }^{1}$ Charité Universitätsmedizin Berlin, Berlin, Germany; ${ }^{2}$ Toronto Western Hospital, Toronto, Canada; ${ }^{3}$ AbbVie, Ljubljana, Slovenia

Background: High inter-reader variability of radiographic sacroiliitis assessment has been reported in a number of previous studies, suggesting its low reliability for the diagnosing and classification of axial spondyloarthritis (axSpA).

Objectives: To compare the results of local versus central scoring of radiographic sacroiliitis in a large multinational cohort of patients (pts) with recently diagnosed axSpA.

Methods: PROOF is a prospective observational study evaluating clinical and radiographic outcomes in axSpA pts in rheumatology clinical practice in 29 countries. Pts with axSpA fulfilling ASAS classification criteria were eligible if diagnosed $\leq 1$ year prior to study enrolment. Radiographs of sacroiliac joints (SIJ) collected at baseline were graded according to the modified New York (mNY) criteria ( $0-4$ for each SIJ). Pts with sacroiliitis of grade $\geq 2$ bilaterally or grade $\geq 3$ unilaterally were classified as ankylosing spondylitis (AS); otherwise pts were classified as non-radiographic axSpA (nr-axSpA). All available radiographs were assessed first by a local reader (LR) and then by a central reader (CR1), who was blinded to the results of the LR. In the case of a disagreement in the classification (AS or nr-axSpA), the radiograph was evaluated by the 2 nd central reader (CR2), who was blinded to the previous assessments and the final classification was made based on the decision of 2 out of 3 readers.

Results: Of the 2126 pts enrolled in PROOF, 1583 were included in this analysis based on evaluable radiographs of the SIJ. Based on the LR judgment, 987 pts were classified as AS and 596 as nr-axSpA, while 1158 were classified as AS and 425 as nr-axSpA according to CR1. Following CR1 assessment, 1146 (72.4\%) pts retained their LR classification, while 437 (27.6\%) pts were classified differently. Of the 437 pts with discrepant classification assessed by CR2, 175 $(40 \%)$ retained their initial LR classification and $265(60 \%)$ were re-classified. The agreement between the CR1 and CR2 (kappa=0.24 [95\% Cl: 0.17-0.32]) was lower than between LR and CR1 (kappa=0.38 [95\% Cl: 0.33-0.42]). Finally, 1039

Figure. Final Classification of Patients with axSpA in Relation to Their Initial Local Classification in the PROOF Study Based on the Assessment of the Radiographic Changes in the Sacroiliac Joints.

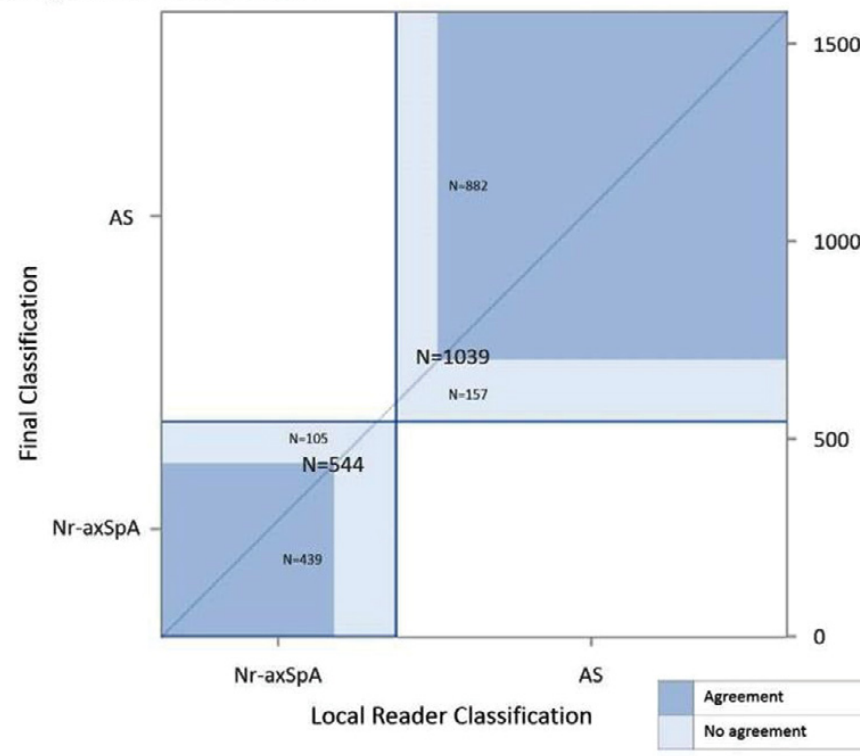

$A S=$ ankylosing spondylitis; $n r-a x S p A=$ non-radiographic axial spondyloarthritis pts were classified as AS and 544 as axSpA; 1321 (83.5\%) pts retained their initial classification and $262(16.5 \%)$ were re-classified (157 from nr-axSpA to $\mathrm{AS}$ and 105 from AS to nr-axSpA). There was a substantial agreement between local and final central classification (kappa $=0.64$ [95\% $\mathrm{Cl}: 0.60-0.68]$, Figure). Importantly, pts initially classified by a LR as nr-axSpA (157/596, 26.3\%) had significantly higher odds (odds ratio=3.0 $(95 \% \mathrm{Cl}: 2.3-3.9)$ of being re-classified compared with pts classified as AS (105/987, 10.6\%).

Conclusions: In the PROOF study, the agreement between local and central classification of pts with axSpA (nr-axSpA vs AS) based on the grading of SIJ radiographs by $\mathrm{mNY}$ criteria was reasonably good. Pts locally classified as $n r-a x S p A$ were three times more likely to be re-classified compared with AS pts, which may be related to difficulty in the assessment of less advanced structural changes.

Acknowledgements: AbbVie funded the PROOF study, contributed to its design and participated in data collection, analysis and interpretation of the data, and in writing, review, and approval of the publication. Medical writing support was provided by Deepa Venkitaramani, PhD, of AbbVie.

Disclosure of Interest: D. Poddubnyy Grant/research support from: AbbVie, Janssen, MSD, Novartis, Pfizer, Consultant for: AbbVie, BMS, Boehringer, MSD, Novartis, Pfizer, and UCB, Speakers bureau: AbbVie, BMS, Janssen, MSD, Novartis, Pfizer, Roche, and UCB, R. Inman Grant/research support from: AbbVie, Amgen, and Janssen, Consultant for: AbbVie, Amgen, Janssen, Lilly, Novartis, and Pfizer, J. Sieper Grant/research support from: AbbVie, Merck, and Pfizer, Consultant for: AbbVie, Janssen, Lilly, Merck, Novartis, Pfizer, and UCB, Speakers bureau: AbbVie, Janssen, Merck, Novartis, Pfizer, Roche, and UCB, H. Haibel Consultant for: Boehringer, MSD, and Novartis, Speakers bureau: AbbVie, MSD, and Pfizer., M. Hojnik Shareholder of: AbbVie, Employee of: AbbVie DOI: 10.1136/annrheumdis-2017-eular.1578

\section{FRI0436 CHRONIC PAIN IN PATIENTS WITH ESTABLISHED AXIAL SPONDYLOARTHRITIS AND ASSESSMENT OF PAIN SENSITIVITY BY COMPUTERIZED PNEUMATIC CUFF PRESSURE ALGOMETRY: RESULTS FROM THE SPARTAKUS COHORT}

E. Mogard ${ }^{1}$, T. Olofsson ${ }^{1}$, A. Bremander ${ }^{2}$, S. Bergman ${ }^{3}$, L.-E. Kristensen ${ }^{4}$ J. Kvistgaard Olsen ${ }^{4}$, J.K. Wallman ${ }^{1}$, E. Lindqvist ${ }^{1} .{ }^{1} / \mathrm{KVL}$, Department of Rheumatology, Lund University, Lund; ${ }^{2}$ School of Business, Engineering and Science, Halmstad University, Halmstad; ${ }^{3}$ Primary health care unit, Department of Public Health and Community Medicine, Institute of Medicine, Sahlgrenska Academy, University of Gothenburg, Gothenburg, Sweden; ${ }^{4}$ The Parker Institute, Department of Rheumatology, Copenhagen University Hospital Fredriksberg and Bispebjerg, Copenhagen, Denmark

Background: Pain is a common symptom in all arthritides, and remains a problem also with better treatment options. In axial spondyloarthritis (ax-SpA), data on chronic pain remain scarce.

Objectives: To study pain distribution, duration and intensity in ax-SpA, and relate this to disease status and measurement of pressure pain sensitivity.

Methods: Consecutive patients $(n=115)$ with clinical ax-SpA diagnoses (ankylosing spondylitis (AS) or undifferentiated axial spondyloarthritis (USpA)) were examined and answered pain questionnaires. Patients were categorised as having no chronic pain (NCP), chronic regional pain (CRP) or chronic widespread pain (CWP). Pressure pain sensitivity was assessed by computerized pneumatic cuff pressure algometry (CPA) on the dominant lower leg, and pain threshold, pain tolerance and temporal summation (assessed by the temporal summation index, TSI) were recorded. Differences in disease status and pressure pain sensitivity between patients with CWP versus NCP were assessed (Chi-square or MannWhitney U-test). Pressure pain sensitivity was also compared between patients with/without unacceptable pain levels (VAS pain $>40$ versus $\leq 40$; Mann-Whitney U-test).

Results: Fifty percent of patients reported CWP, irrespective of clinical diagnosis (AS 47\%, USpA 53\%), and more women than men reported CWP (59\% versus $37 \%, p<0.001)$. Only $18 \%$ of all patients reported NCP. Overall, higher disease

\begin{tabular}{lccccc}
\hline Mean (SD) unless indicated & $\begin{array}{c}\text { All } \\
\text { cases } \\
\mathrm{n}=115\end{array}$ & $\begin{array}{c}\text { Non } \\
\text { chronic } \\
\text { pain (NCP) } \\
\mathrm{n}=20\end{array}$ & $\begin{array}{c}\text { Chronic } \\
\text { regional } \\
\text { pain (CRP) } \\
\mathrm{n}=38\end{array}$ & $\begin{array}{c}\text { Chronic } \\
\text { widespread } \\
\text { pain (CWP) } \\
\mathrm{n}=57\end{array}$ & $\begin{array}{c}\text { NCP vs CWP } \\
\text { p value }\end{array}$ \\
\hline Female sex, $\mathrm{n}(\%)$ & $66(57)$ & $6(30)$ & $21(55)$ & $39(68)$ & 0.004 \\
Age, years, years & $53(13)$ & $52(16)$ & $49(13)$ & $55(12)$ & 0.384 \\
Disease duration, years & $25(14)$ & $24(14)$ & $22(13)$ & $29(14)$ & 0.148 \\
HLA-B27 positive, yes (\%) & $83(74)$ & $14(78)$ & $30(79)$ & $39(68)$ & 0.560 \\
AS/USpA (ICD-10) $\mathrm{n}$ & $60 / 55$ & $13 / 7$ & $19 / 19$ & $28 / 29$ & 0.299 \\
VAS pain, 0-100 & $37(27)$ & $15(18)$ & $32(26)$ & $49(24)$ & $<0.001$ \\
VAS global & $38(26)$ & $19(22)$ & $32(26)$ & $48(22)$ & $<0.001$ \\
VAS fatigue & $40(28)$ & $23(23)$ & $33(28)$ & $51(26)$ & $<0.001$ \\
BASDAl & $3.5(2.3)$ & $1.6(1.6)$ & $3.0(2.0)$ & $4.9(2.1)$ & $<0.001$ \\
BASFI & $2.5(2.4)$ & $1.1(1.4)$ & $1.8(2.3)$ & $3.7(2.4)$ & $<0.001$ \\
BASMI & $3.1(1.6)$ & $2.9(1.6)$ & $2.9(1.9)$ & $3.3(1.4)$ & 0.255 \\
ASDAS-CRP & $2.1(1.0)$ & $1.2(0.7)$ & $1.8(0.9)$ & $2.7(0.8)$ & $<0.001$ \\
Pain threshold ,kPa & $30.1(14.4)$ & $33.7(18.1)$ & $30.7(11.5)$ & $27.8(14.8)$ & 0.216 \\
Pain tolerance, kPa & $62.1(26.5)$ & $71.6(29.5)$ & $63.0(25.0)$ & $56.8(25.6)$ & 0.069 \\
TSI & $0.60(0.59)$ & $0.53(0.46)$ & $0.60(0.57)$ & $0.63(0.66)$ & 0.189 \\
\hline
\end{tabular}

